\section{Risk measures and the risk-return paradox: an analysis in the context of the economic crisis}

\author{
Rosa María Muñoz ${ }^{1}$ \\ Jesús David Sánchez de Pablo' \\ Yolanda Salinero' ${ }^{1}$ \\ Isidro Peña ${ }^{1}$ \\ ${ }^{1}$ University of Castilla-La Mancha, Business \\ Administration, Ciudad Real, Spain
}

Recebimento:

$12 / 18 / 2018$

Aprovaçáo:

09/18/2019

Editor responsável:

Prof. Dr. Javier Montoya Del

Corte

Avaliado pelo sistema:

Double Blind Review

\begin{abstract}
Purpose - The purpose of this study is to analyze, in the context of the last economic crisis, the prediction capacity of the different risk measures and the relationship between risk and return.

Design/methodology/approach - We selected three risk measures constructed using annual accounting data obtained from Spanish companies. A logistic regression was then developed to verify whether the companies' predictions were eventually correct, considering those companies that were able to survive the crisis. A multiple linear regression was subsequently employed in order to review Bowman's paradox, that is, in the risk-return relationship.
\end{abstract}

Findings - The research results support the two hypotheses formulated:

1) variability measures of risk have a greater predictive power than that of downside risk measures;

2) the risk-return paradox is more likely to exist in the more uncertain environment of a pre-crisis period of time.

Originality/value - Managers could employ the frameworks developed in this study as important diagnostic tools in order to attain advance warning of whether an organization may be close to failure. An analysis of this nature would then allow a firm to take appropriate action to arrest the process.

Keywords - global crisis, corporate failure, prediction capacity, risk, risk-return paradox

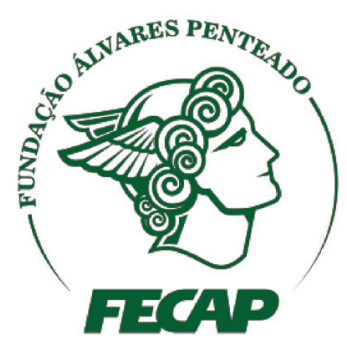

Revista Brasileira de Gestáo de Negócios

DOI: $10.7819 /$ rbgn.v22i2.4049 


\section{Introduction}

The first indications of the global crisis appeared in August 2007, when there were problems in the interbank lending market and the subprime mortgage market began to implode. It continued with a slowdown in the U.S. economy and the sale of Bear Stearns in March 2008, after which several economic disasters occurred, such as the bankruptcy of Lehman Brothers, the sale of Merrill Lynch, and the collapse of AIG, Fannie Mae, and Freddie Mac in September 2008 (Heracleous \& Werres, 2016). Governments and businesses have subsequently been struggling to return to normal. Europe had similar banking problems. The "great financial rescue" of banks by governments in 2008 stopped further collapse, but the age of austerity still continues, with significant effects for nations, companies, families, and individuals (Starkey, 2015). One of the questions researchers and economists attempt to answer when crises occur is whether it is possible to predict them (Lukason, Laitinen, \& Suvas, 2016) and risk is an important variable in this respect. In this research, we present various risk measures and analyze their prediction capacity by considering the global crisis of 2008. After reviewing the main theories, we adopt an integrative risk perspective and formulate the following hypothesis:

$\mathbf{H}_{\mathbf{1}}$ - Variability measures of risk have a greater predictive power than that of downside risk measures.

As a complement, we also develop another line of research in relation to the well-known riskreturn paradox, i.e., we analyze the relationship between risk and return. This issue has already been studied from different points of view and with different results. We employ the perspective that considers that the risk-return paradox appears to be dependent upon the time period to formulate the following hypothesis:

$\mathbf{H}_{2}$ - The risk-return paradox was more likely to exist in the more uncertain environment of the period of time just before the beginning of the 2008 economic crisis.

In order to test the first hypothesis, we created two groups of companies, the first of which was formed of those companies that were able to survive the crisis in question, while the second was composed of those that did not. We then generated the selected risk measures using data from the period just before the crisis and subsequently verified whether their predictions eventually proved to be correct. This objective was attained through the development of a logistic regression, while the second hypothesis was tested by examining Bowman's paradox using multiple linear regression.

The research results support the two hypotheses formulated:

1) variability measures of risk have a greater predictive power than that of downside risk measures;

2) the risk-return paradox is more likely to exist in the more uncertain environment of a pre-crisis period of time.

The results obtained from our research therefore support the integrative risk perspective, which suggests that managers should consider all important aspects to which a company is exposed, and not only the downside risk or below-target performance. Moreover, the riskreturn paradox appears to be dependent upon the time period: it would appear to be more likely in more uncertain environments, such as at the beginning of a global crisis.

The study is organized as follows. First, we present the risk variable and the different ways in which it can be measured, after which we analyze the relationship between risk and return, highlighting previous management research and its different contributions regarding the issue. We go on to explain the sample and the methodology, and then present the main results. The final section provides our conclusions. 


\section{Risk}

Risk has become an important variable in many areas of strategy research. It has been included in research on business strategy and the characteristics of industry (Andersen, Denrell, \& Bettis, 2007; e.g., Cool, Dierickx, \& Jemison, 1989; Oviatt \& Bauerschmidt, 1991; Woo, 1987), corporate diversification (Amit \& Livnat, 1988; Belderbos, Tong, \& Wu, 2014; Bettis \& Mahajan, 1985; Kim, Hwang, \& Burgers, 1993), and organizational processes and structures (Hoskisson, 1987; Jemison, 1987). In some cases, risk is used to describe managerial choices associated with uncertain outcomes (managerial risk taking). In others, risk is a characteristic of organizations experiencing volatile income streams (organizational risk) (Palmer \& Wiseman, 1999).

Historically, firms have managed different kinds of risk separately. Bannister and Bawcutt (1981) proposed that risk management requires multiple disciplines working together to manage future uncertainty, which requires the alignment of risk management with corporate governance and strategy. In this respect, Andersen (2008) considers three risk perspectives: 1) conventional risk management practices, which have typically focused on the containment of economic risks and environmental hazards, where exposures can be covered in derivative and insurance markets; 2) the enterprise risk management approaches, which also consider operational risks within an integrative framework often implemented in conjunction with internal auditing and control systems; 3) the total risk management perspective, which considers all risk categories from a more holistic perspective, including strategic risks in which the pursuit of upside potential is as important as counteracting downside losses. Bromiley, McShane, Nair, and Rustambekov (2015) claim that enterprise risk management incorporates not only traditional risks, such as product liability and accidents, but also strategic risks, such as product obsolescence or competitor actions. That is, a systematic and integrated approach to managing the total number of risks that a company confronts is taking on importance in the research community. An integrative risk management perspective suggests that all a firm's important exposures should be considered. This is difficult to achieve in practice, and the reality is that conventional risk management is usually associated with corporate finance departments and often fails to incorporate marketing, strategy, product development, etc. into its risk assessments. In this respect, many regulators, executives, and academics have advocated Enterprise Risk Management, which can be defined as "the idea that emerged in the late 1990s that a firm should identify and (when possible) measure all of its risk exposures, including operational and competitive risks, and manage them within a single unified framework in contrast to the silo approach to risk management" (Harrington, Niehaus, \& Risko, 2002).

Recent history raises doubts about the effectiveness of risk management as previously practiced. In the economic downturn caused by the crisis in 2008, the most sophisticated practitioners of risk management (e.g., the Wall Street banks) suffered most heavily, causing tremendous damage to international economies (Bromiley et al., 2015). However, recent studies show that Enterprise Risk Management has a positive effect on a firm's value in the context of an emerging economy (Anton, 2018).

In this paper we deal with this claim by considering the 2008 crisis as the reference point in order to verify the prediction capacity of some of the most common risk measures.

\section{I Risk measures}

Previous studies have employed a variety of risk measures derived from stock return data and accounting in an attempt to capture the variability of firms' performances. The most common measures are the variance of return on assets (ROA) and return on equity (ROE), 
and systematic (i.e., beta) and unsystematic risk derived from historical stock returns. Three considerations have led many researchers to evaluate total risk rather than systematic risk (Cool \& Schendel, 1988): (1) the empirical difficulty involved in estimating the beta at the business level in the absence of financial market data; (2) the fact that the beta is, both empirically and theoretically, related to total risk; and (3) management is responsible for a wider group of stakeholders than just shareholders, thus making total risk a prominent concern. The measurement of risk in terms of standard deviation has, therefore, been employed rather than the beta in many studies.

Despite the widespread use of variability measures, behavioral decision theory suggests that this approach may not reflect managers' and investors' conceptualizations of risk. Criticisms can also be found in the strategic management and finance literature. Authors in these fields propose that investors and managers are averse to downside risk, i.e., below-target performance. Miller and Reuer (1996) introduce three categories for downside risk measures that include measures based on historical performance, a downside version of the capital asset pricing model (CAPM), and stock analysts' earnings forecasts. After considering the sample characteristics, that is, firms that do not operate in the stock market, we judged the first to be the most appropriate and therefore chose and modeled it using lower partial moments (LPM), as suggested by Fishburn (1977). LPM refers to the inclusion of only the left-hand (downside) tail of the returns distribution in the calculation.

Using discrete historical returns data, the equation can be written as (Miller \& Reuer, 1996):

$$
\operatorname{LPM} \alpha(\tau, j)=(1 / N) \sum_{r j \tau}^{\tau}\left(\tau-r_{j}\right)^{\alpha}, \alpha \geq 0
$$

where the risk for firm $\mathbf{j}$ can be defined in terms of a target level of return, denoted as $t$, and the relative importance of returns below the target measured by a parameter a. $\mathrm{N}$ is the number of return observations.

If we consider the return distribution for two different firms with normal distributions but different means, the main difference in relation to the traditional variance (or standard deviation) is that if we use the LPM (probability of loss), risk is measured as the area under the curve to the left of a particular target level. That is, if companies in an industry share a common aspiration level, such as the median performance level, a firm that consistently underperforms the industry median will have a higher risk level than a firm that consistently outperforms the industry median (Miller \& Reuer, 1996).

It is necessary to identify the measure of returns and the appropriate values for $\mathrm{t}$ and a. The specification of a makes implicit assumptions about the nature of organizational utility. Theoretical considerations generally give rise to values of a ranging from zero to two. A value of between zero and one is consistent with risk seeking (a convex utility function), while a value of more than one implies risk aversion (a concave utility function) and a value equal to one indicates risk neutrality (Kahneman \& Tversky, 1979). As this research employs downside and variability measures of organizational risk, we consider it more appropriate to construct the LPM as a second-order measure, that is, $a=2$. We also used the root of the LPM in order to ensure consistency when making a comparison with standard deviation measures.

There are many possibilities as regards the target level $\mathrm{t}$, but we consider that the most appropriate is to allow the target return to vary over time, that is, we assumed adaptive aspirations. We therefore followed the suggestions of Miller and Reuer (1996) and made the simplifying assumption that firms look at the industry average performance and use the industry average for ROA and ROE as proxies for organizational targets.

In order to verify the differences between downside measures and variability measures, we 
also generated the standard deviation of ROA and ROE and a bankruptcy risk measure, Altman's Z (according to Altman (1983), a downside concept of risk is also implicit in strategy studies incorporating Altman's Z).

Altman's $Z$ is a discriminant function that distinguishes companies with a high risk of bankruptcy from those with a low risk. It is an inverse indicator, that is, the higher the result, the less likely bankruptcy is. Altman's $Z$ is defined as (Altman, 1993):

$$
\mathrm{Z}=1.2 \mathrm{X}_{1}+1.4 \mathrm{X}_{2}+3.3 \mathrm{X}_{3}+0.6 \mathrm{X}_{4}+1.0 \mathrm{X}_{5}
$$

where

$\mathrm{X}_{1}=$ working capital/total assets

$\mathrm{X}_{2}=$ retained earnings/total assets

$\mathrm{X}_{3}=$ earnings before interest and taxes/total assets

$\mathrm{X}_{4}=$ market value of equity/book value of total liabilities

$\mathrm{X}_{5}=$ sales/total assets (all the variables are in percentages except this one).

It has been suggested that the Z-Score model is an accurate forecaster of failure for up to two years prior to distress and that accuracy diminishes substantially as the time increases.

As will be noted, the model is suitable for publicly traded entities (since the first variable requires stock price data). In order to extend its utility, Altman developed two other equations for enterprises that are not in the stock market and for non-manufacturing companies. Considering the characteristics of our sample, it is necessary to use the equation for non-publicly traded firms, which is:

$$
Z^{\prime}=0.717 X_{1}+0.847 X_{2}+3.10731 X_{3}+0.420 X_{4}+0.998 X_{5}
$$

where the fourth variable is:

$\mathrm{X}_{4}=$ book value of equity/ book value of total liabilities.

Although some researchers in various fields propose that managers and investors are averse to downsize risk, we consider an integrative risk perspective to be more suitable. In this respect, we formulated the following hypothesis considering all the important aspects to which a company is exposed.

$\mathbf{H}_{\mathbf{1}}$ - Variability measures of risk have a greater predictive power than that of downside risk measures.

\section{The Risk-Return Paradox}

The concept of risk is central to strategic management. Many authors have also paid attention to the relationship between firms' risks and their returns. A positive association between these two variables is expected, considering the usual and plausible assumption of risk-averse actors. However, when measuring risk as the variance of a series of returns, Bowman (1980) obtained a negative relationship between risk and return, which is known as Bowman's paradox or the risk-return paradox. That is, Bowman noted the existence of a risk-return paradox for strategic management that clearly runs counter to the hypothesis of a positive correlation between risk and return commonly advanced in finance and economic theory (Fiegenbaum \& Thomas, 1986).

Various explanations for the risk-return paradox have been proposed (Henkel, 2009): those based on prospect theory, which suggest that it may be the result of firms with low performance taking on additional risk (Bowman, 1982; Fiegenbaum \& Thomas, 1990; Gooding, Goel, \& Wiseman, 1996; Johnson, 1992); strategic and organizational factors (Andersen et al., 2007; Bettis \& Mahajan, 1985; Bowman, 1980); and model misspecifications (Henkel, 2000; Ruefli, 1990).

The most common explanation today is probably the effect of performance relative to a reference point and its impact on managerial risk taking, as discussed by prospect theory and the behavioral theory of the firm. Following this explanatory rationale, high performance is associated with risk aversion, while poor performance is associated with risk-seeking 
behavior. Negative risk-return relationships arise as managers in the underperforming firms decide to undertake riskier actions in order to increase returns, thus implying that individual decisionmaking behavior aggregates into organizational outcome effects. The second explanatory rationale attempts to show that good management practices can make a difference. Inverse riskreturn relationships could be the result of the heterogeneity of a firm's strategic management capabilities. This stream of research has been less grounded in theory than the first approach, and has tended to advocate normative premises for strategic management as an effective way in which to manage both risk and return (Andersen et al., 2007).

Positive risk-return relationships have commonly emerged in cross-sectional studies examining both firm-level and industry-level data. Negative risk-return relationships emerge when alternative measures are included in studies. These measures range from the nature of industry, diversification strategies, the firm's size, the period studied, risk attitudes, and risk measures (Fiegenbaum \& Thomas, 1988). From another perspective, the risk-return paradox appears to be dependent on the time period adopted in the study. For example, it is clear from a number of sources that the 1960s and 1970s had markedly different strategic characteristics (Gluck, Kaufman, \& Walleck, 1980; Hofer \& Schendel, 1978). The 1960s were a boom decade with low inflation rates, stable market structures, and in which growth seemed eternal. The 1970s business environment was, however, less predictable, ill-structured, and with increasing rates of environmental change and competitive pressure. As a result, the risk-return paradox was more evident in the environment of the 1970s than in that of the 1960s (Figenbaum \& Thomas, 1986). After considering these claims, we formulated the following hypothesis:

$\mathbf{H}_{2}$ - The risk-return paradox was more likely to exist in the more uncertain environment of the period of time just before the beginning of the 2008 economic crisis.

\section{Methodology}

The main objective of this empirical analysis is to verify the predictive capacity of some of the most widely used risk measures. It is generally accepted that one of the most important economic crisis to have occurred in a considerable amount of time began in 2008. We therefore constructed two groups of companies: the first is formed of those companies that were able to survive that crisis and the second is formed of those companies that did not. We generated the selected risk measures using data from the period just before the crisis and then checked whether or not the predictions eventually proved to be correct. This objective was attained through the development of a logistic regression. We then re-examined Bowman's paradox using multiple linear regression.

\section{I Risk}

We selected three measures of organizational risk used in strategy research: one downside measure, the Lower Partial Moment (LPM); one variability measure, the standard deviation; and one bankruptcy risk measure, Altman's Z. The measures were constructed using annual accounting data from the Spanish SABI data base covering the 2006-2008 period. The sample was created in 2015 and has the following characteristics:

a) 80 inactive and 589 active companies (both types of companies were active during the 2006-2008 period but the first group was no longer active in 2015);

b) firms with at least 250 employees (companies with fewer employees are considered to be small and medium-sized in the European Union, and we consider it more difficult to attain reliable data from these types of firms);

c) Spanish companies;

d) companies not listed in the stock market; 
e) industrial activity [two-digit National Classification of Economic Activities (Clasificación Nacional de Actividades Económicas - CNAE), from 10 to 32]. Industries with less than 15 firms were eliminated.

We used the industry averages for ROA and ROE that appear in the annual report published by the Bank of Spain as proxies for organizational targets in order to construct the LPM.

\subsection{Corporate performance}

In this case, returns are measured by the means of return on assets (ROA) and return on equity (ROE). ROA is defined as income after tax but before extraordinary items divided by total assets. ROE is defined as income after tax but before extraordinary items divided by total common equity.

In a previous task, we verified the existence of outliers in the database. Not all outliers are influential in a regression analysis. We then ran the regression with all the data and checked residual plots. Of interest in this particular case is the Residuals vs. the Leverage plot. When cases are outside Cook's distance (meaning they have high Cook's distance scores), the cases have an influence on the regression results. This was not the case the outliers were not influential (low leverage and low residual), and so we did not remove them and we reran the regression.

\subsection{Logistic regression}

Logistic regressions are an extension of regressions but with an outcome variable that is categorical and predictor variables that are continuous or categorical. This means that, given certain other information, it is possible to predict to which of two categories a company is likely to belong. In simple linear regressions, the outcome variable $\mathrm{Y}$ is predicted from the equation of a straight line. In logistic regressions, rather than predicting the value of a variable $\mathrm{Y}$ from several predictor variables, we predict the probability of $\mathrm{Y}$ occurring given known values of Xs.

The prediction capacity of the risk measurements is tested using a logistic regression in which the dependent variable is dichotomic ( $1=$ the company survives, $0=$ the company does not survive). We specifically tested whether a firm's survival can be anticipated using indicators such as the Lower Partial Moment, the standard deviation, and the Altman's Z (independent variables). The principal results attained are shown in Tables 1 and 2.

Table 1

\section{Logistic regression (variables in the equation)}

\begin{tabular}{lcccccc}
\hline Variables & B & S.E. & Wald & df & Sig. & Exp (B) \\
\hline Std. deviation ROA & $-0,034$ & 0,018 & 3,503 & 1 & 0,061 & 0,966 \\
Constant & 2,110 & 0,149 & 200,100 & 1 & 0,000 & 8,252 \\
\hline
\end{tabular}

Note. Forward Stepwise (Wald) method, first step

Table 2

\section{Logistic regression (variables not in the equation)}

\begin{tabular}{lccc}
\hline Variable & Score & Df & Sig. \\
\hline Altman's Z & 0,013 & 1 & 0,910 \\
LPM ROA mean & 0,382 & 1 & 0,537 \\
LPM ROE mean & 0,395 & 1 & 0,530 \\
Std. deviation ROE & 0,738 & 1 & 0,390 \\
\hline
\end{tabular}


The fifth column in Table 1 shows which parameters are significant according to the test. The parameter that accompanies the standard deviation of ROA is significant with a confidence margin of $90 \%$. When considering the sign of parameter $\mathrm{B}$, the greater the standard deviation of ROE, the less probable it is that the company will survive. The remaining variables do not have a significant influence on the model and we can, therefore, conclude that these variables do not have predictive power for our sample. Standard deviation is the only variable that could be useful in predicting the future survival of a company in the marketplace, thus supporting Hypothesis 1.

With regard to the goodness of fit, three alternative measures were considered: the Cox and Snell R2, the R2-Nag (the percentage of variation explained by the model's independent variables oscillates between 5\% and 9\%), and the HosmerLemeshow statistic (in our case, this is 0.220 for a Chi-square of 10,688 with 8 degrees of freedom, signifying that an acceptable fit exists).

\subsection{Multiple linear regression}

In order to test the risk-return paradox, we developed a multiple linear regression analysis including the following control variables.

\subsection{Firm size}

Company size represents prior performance and may reflect the availability of organizational slack that could affect risk management capabilities and corporate performance outcomes (Juul, 2008). Firm size, which is measured as the natural logarithm of total assets in order to correct for positive skew in the data, was therefore included as a control variable in the regression analyses.

\subsubsection{Knowledge-intensive industry}

It is well known that different competitive environments may lead to systematic differences in corporate performance levels across industries. Thus, we consider that it is particularly important to pay attention to companies in knowledgeintensive industries. From a resource-based view, these diverse sets of knowledge can constitute firm-specific resources that may lead to a sustainable competitive advantage. In the sample, the knowledge-intensive industries include pharmaceutical preparations, computer and office equipment, electrical equipment, and industrial machinery, which are deemed particularly dependent on specialized knowledge. We therefore, introduced a dummy variable that takes the value 1 if the firm operates in these industries and 0 otherwise. This was applied to 131 firms, making up 20 per cent of the total sample.

The measures of risk and corporate performance were averaged over the three years from 2006 to 2008 in order to eliminate spurious year-on-year effects throughout the period being studied. The hypothesis was tested by employing multiple regression analyses and using the whole sample made up of 659 companies. The test used the ROA and ROE as dependent variables and the measures of risk, firm size, and the knowledgeintensive industry dummies as independent variables.

The regressions were tested for possible multicollinearity and outlier effects. Datasets causing prediction errors in excess of three times the standard deviation were excluded from the sample (ten companies, meaning that the whole final sample was made up of 659 firms). No multicollinearity problems were registered and the VIFs did not exceed the level indicating potential multicollinearity problems.

Table 3 shows that a strong interrelationship among the independent variables does not exist and the results of the multiple regressions are, therefore, not distorted in this respect. 
Table 3

Correlations and descriptive statistics

\begin{tabular}{|c|c|c|c|c|c|c|}
\hline MODEL I & ROA & Size & Knowledge-intensive & SDROA & Mean & SD \\
\hline $\mathrm{ROA}$ & & & & & 4,9678 & 10,90 \\
\hline Size & $0,069^{* *}$ & & & & 11,52 & 1,278 \\
\hline Knowledge-intensive & $0,109^{* * *}$ & $-0,006$ & & & 0,20 & 0,402 \\
\hline SDROA & $-0,312^{* * *}$ & $-0,116^{* * *}$ & $-0,023$ & & 4,1355 & 5,108 \\
\hline
\end{tabular}

${ }^{*} \mathrm{p}<0.1{ }^{* *} \mathrm{p}<0.05{ }^{* * *} \mathrm{p}<0.01$

\begin{tabular}{|c|c|c|c|c|c|c|}
\hline MODEL II & ROA & Size & Knowledge-intensive & $\mathrm{Z}$ & Mean & SD \\
\hline ROA & & & & & 4,9678 & 10,88 \\
\hline Size & $0,09^{* *}$ & & & & 11,56 & 1,26 \\
\hline Knowledge-intensive & $0,112^{* * *}$ & $-0,001$ & & & 0,20 & 0,39 \\
\hline Z & $0,367^{* * *}$ & $-0,111^{* * *}$ & 0,016 & & 1,47 & 0,909 \\
\hline
\end{tabular}

${ }^{*} \mathrm{p}<0.1 \quad{ }^{* *} \mathrm{p}<0.05{ }^{* * *} \mathrm{p}<0.01$

\begin{tabular}{|c|c|c|c|c|c|c|}
\hline MODEL III & ROA & Size & Knowledge-intensive & LPMROA & Mean & SD \\
\hline ROA & & & & & 4,968 & 10,90 \\
\hline Size & $0,069^{* *}$ & & & & 11,52 & 1,28 \\
\hline Knowledge-intensive & $0,109^{* * *}$ & $-0,006$ & & & 0,20 & 0,402 \\
\hline LPMROA & $-0,449^{* * *}$ & $-0,136^{* * *}$ & $-0,057^{*}$ & & 184,28 & 593,4 \\
\hline
\end{tabular}

${ }^{*} \mathrm{p}<0.1 \quad{ }^{* *} \mathrm{p}<0.05 \quad{ }^{* * *} \mathrm{p}<0.01$

\begin{tabular}{|c|c|c|c|c|c|c|}
\hline MODEL IV & ROE & Size & Knowledge-intensive & SDROE & Mean & SD \\
\hline ROE & & & & & 13,62 & 106,12 \\
\hline Size & $-0,039$ & & & & 11,52 & 1,279 \\
\hline Knowledge-intensive & $0,074^{* *}$ & $-0,006$ & & & 0,2 & 0,402 \\
\hline SDROE & $-0,111^{* * *}$ & $-0,037$ & $-0,022$ & & 32,44 & 150,944 \\
\hline
\end{tabular}

${ }^{*} \mathrm{p}<0.1{ }^{* *} \mathrm{p}<0.05{ }^{* * *} \mathrm{p}<0.01$

\begin{tabular}{|c|c|c|c|c|c|c|}
\hline MODEL V & ROE & Size & Knowledge-intensive & $\mathrm{Z}$ & Mean & SD \\
\hline ROE & & & & & 13,22 & 107,82 \\
\hline Size & $-0,035$ & & & & 11,56 & 1,26 \\
\hline Knowledge-intensive & $0,072^{* *}$ & $-0,001$ & & & 0,20 & 0,4 \\
\hline Z & 0,043 & $-0,111^{* * *}$ & 0,016 & & & \\
\hline
\end{tabular}

${ }^{*} \mathrm{p}<0.1 \quad{ }^{* *} \mathrm{p}<0.05 \quad{ }^{* * *} \mathrm{p}<0.01$

\begin{tabular}{|c|c|c|c|c|c|c|}
\hline MODEL VI & ROE & Size & Knowledge-intensive & LPMROE & Mean & SD \\
\hline ROE & & & & & 13,62 & 16,12 \\
\hline Size & $-0,039$ & & & & 11,52 & 1,278 \\
\hline Knowledge-intensive & $0,074^{* *}$ & $-0,006$ & & & 0,20 & 0,402 \\
\hline LPMROE & $-0,131^{* * *}$ & $-0,023$ & $-0,027$ & & 250,83 & 705,4 \\
\hline
\end{tabular}

${ }^{*} \mathrm{p}<0.1 \quad{ }^{* *} \mathrm{p}<0.05 \quad{ }^{* * *} \mathrm{p}<0.01$ 
The results of the multiple regression analysis are shown in Tables 4 and 5 .

Table 4

\section{Results of regression analyses}

\begin{tabular}{lccc}
\hline & & ROA & III \\
\cline { 2 - 3 } & I & II & 0,265 \\
\hline Organizational size & 0,920 & $3,636^{* * *}$ & $2,422^{* *}$ \\
Knowledge-intensive industries & $2,784^{* * *}$ & $2,931^{* * *}$ & \\
Std. deviation ROA & $-8,295^{* * *}$ & & $10,458^{* * *}$ \\
Altman's Z mean & & & $-12,689^{* * *}$ \\
LPM ROA mean & & 0,159 & 0,205 \\
Adjusted R & & 0,000 & 0,000 \\
F-significance & 0,105 & 0,000 & \\
\hline
\end{tabular}

${ }^{*} \mathrm{p}<0.1 \quad{ }^{* *} \mathrm{p}<0.05{ }^{* * *} \mathrm{p}<0.01$

Table 5

\section{Results of regression analyses}

\begin{tabular}{lccc}
\hline & & ROE & II \\
\cline { 2 - 3 } & I & $-0,779$ & $-1,089$ \\
\hline Organizational size & $-1,116$ & $1,837^{*}$ \\
Knowledge-intensive industries & $1,859^{*}$ & $1,821^{*}$ & \\
Std. deviation ROE & $-2,897^{* * *}$ & & 0,976 \\
Altman's Z mean & & & $-3,387^{* * *}$ \\
LPM ROE mean & & 0,003 & 0,019 \\
Adjusted R & & 0,001 \\
F-significance & 0,015 & 0,164 & 0,005 \\
\hline
\end{tabular}

${ }^{*} \mathrm{p}<0.1 \quad * * \mathrm{p}<0.05 \quad * * * \mathrm{p}<0.01$

The regression coefficients of the standard deviation as regards both performance measures are significant and negative (Model I).

The regression coefficient of the Altman's $\mathrm{Z}$ for the ROA measure is significant and positive, but is not significant if we consider the ROE measure (Model II).

The regression coefficients of the LPM for both performance measures are significant and negative (Model III).

As will be noted, the research results provide support for Hypothesis 2. These findings tend to suggest that the choice of time period (which itself may reflect wider environmental influences) may critically offset the finding of a negative association between risk and return. However, when using Altman's $Z$ as a risk proxy, we attain conclusions that are the opposite of those obtained using variability measures. This observation is an extension of Miller and Bromiley's (1990) work, which did not consider Altman's $Z$ among the risk proxies examined.

Of the control variables, we find that Size is not significant (only in the second model of the first regression), while Knowledge-intensive industries is significant in all situations. As expected, knowledge constitutes a resource that may lead to a sustainable competitive advantage. 


\section{Conclusions}

The empirical analysis carried out herein is based on an estimation of companies' risk during the 2006-2008 period. The impact of the financial crisis was particularly strong in Spain, dramatically affecting the business environment for firms. From studying the GDP per capita of the largest European economies in the 2008-2012 period, it can be noted that Spain, together with Italy, saw one of the biggest reductions (Campiglio, 2014), meaning that Spain represents a relevant context in which to investigate the effects of the economic crisis on firms. The choice of 2008 as a cut-off point was made by taking into account when the global crisis started to have significant effects on the real economy in Europe and, consequently, on firms' strategic behaviors.

Understanding risk in organizations remains an important goal in strategic management. This endeavor has, however, been hampered by confusion over the meaning and the measurement of risk. Given the disparate meanings, it is not surprising that several independent streams of research have emerged.

Despite the widespread use of variability measures as risk proxies, behavioral decision theory suggests that an approach of this nature may not reflect managers' and investors' conceptualizations of risk. Researchers in various fields propose that managers and investors are averse to downside risk and empirical strategy research using downside risk may, therefore, provide a greater explanatory power than previous studies using variability measures of risk.

However, an integrative risk perspective suggests that all important exposures should be considered, including financial prices, accidents, environmental hazards, political trends, economic conditions, changing customers' needs, etc. While risk management is often conceived as procedures that identify and manage downside risk events, other responsive processes are equally important, such as the development of new business opportunities and their execution in order to take advantage of evolving competitive scenarios. The results obtained from our research support Hypothesis 1 and are in the line of this second perspective: variability measures of risk have a greater predictive power than that of the downside risk measures. These have been the most common measures included in research by many authors (Bowman, 1980; Bromiley, 1991; Fiegenbaum \& Thomas, 1988; Oviatt \& Bauerschmidt, 1991). As Juul (2008) claims, total risk management is the ability to respond effectively to all exogenous market factors beyond managerial control, so the variability of corporate earnings is damped. This ability includes practices to reduce downside exposures, such as financial hedging, insurance contracting, and management controls, along with approaches to enhance upside gains through innovation, responsive decisionmaking, redeployment of resources, etc.

In relation to the second analysis developed, existent research on decision making, which is mostly based on the behavioral theory of the firm and prospect theory, acknowledges that, when confronted with an economic crisis, firms are confronted with a dilemma: whether to avoid risk and pursue conservative strategies, or to take risks to extend their competitive advantages (Zona, 2012). The risk-return paradox appears to be dependent upon the time period adopted in the study. It appears more likely in more uncertain, less predictable environments such as the beginning of the recent economic crisis. The markedly different and less stable environmental and economic conditions of this period of time may provide some justification for the risk-return paradox. According to Bowman (1982), the negative risk-return association is also explained by the risk-seeking attitudes of more troubled firms. Proponents of the risk-taking perspective emphasize that firms may actually respond to economic adversity by undertaking greater, not lower, risk (Cerrato, Alessandri, \& Depperu, 2016).

There are a number of important directions for future research and some limitations in relation to this study. Risk-return relationships 
should be studied more closely at the level of the individual industry and should be extended to include more sectors, and not only industrial activity. The definition of appropriate measures of risk should be considered, as should the potential biases in the calculation and interpretation of risk measures. This research and other similar studies could be criticized for aggregating the risk-return analysis across time periods rather than analyzing the dynamic characteristics of risk-return measures on an annual basis, as some authors propose. This paper has this limitation and it would, therefore, also be desirable in future research to test the empirical models in other periods of time, not only just before the beginning of an economic crisis.

In terms of implications for practice, the frameworks developed in this study can be employed as important diagnostic tools by senior managers, strategic planners, or consultants in order to attain advance warning of whether an organization is coming close to failure. Such an analysis would then allow a firm to take appropriate actions to arrest the process, which would be crucial in order to achieve a successful turnaround.

\section{References}

Altman, E. I. (1983). Corporate distress: A complete guide to predicting, avoiding and dealing with bankruptcy. New York: John Wiley \& Sons.

Altman, E. I. (1993). Corporate financial distress and bankruptcy. New York: John Wiley \& Sons.

Amit, R., \& Livnat J. (1988). Diversification and the risk-return trade-off. Academy of Management Journal, 31(1), 154-166.

Andersen, T. J. (2008). The performance relationship of effective risk management: Exploring the firm-specific investment rationale. Longe Range Planning, 41(2), 155-176.

Andersen, T. J., Denrell, J., \& Bettis, R.A. (2007). Strategic responsiveness and Bowman's risk- return paradox. Strategic Management Journal, 28, 407-429.

Anton, S. G. (2018). The impact of enterprise risk management on firm value: Empirical evidence from Romanian non-financial firms. Engineering Economics, 29(2), 151-157.

Bannister, J. E., \& Bawcutt, P. A. (1981). Practical risk management. London: Whitherby and Company Ltd.

Belderbos, R., Tong, T. W., \& Wu, S. (2014). Multinationality and downside risk: The roles of option portfolio and organization. Strategic Management Journal, 35, 88-106.

Bettis, R. A., \& Mahajan, V. (1985). Risk/return performance of diversified firms. Management Science, 31(7), 785-799.

Bowman, E. H. (1980). A risk-return paradox for strategic management. Sloan Management Review, 21, 17-33.

Bowman, E. H. (1982). Risk seeking by troubled firms. Sloan Management Review, 23, 33-42.

Bromiley, P. (1991). Testing a causal model of corporate risk taking and performance. Academy of Management Journal, 34(1), 37-59.

Bromiley, P. McShane, M., Nair, A., \& Rustambekov, E. (2015). Enterprise risk management: Review, critique and research directions. Longe Range Planning, 48(4), 265-276.

Campiglio, L. (2014). Unemployment, consumption, investment, inflation and current account, Istituto de Politica Economica. Universita Cattolica del Sacro Cuore, Quaderno n.67, Italy.

Cerrato, D., Alessandri, T., \& Depperu, D. (2016). Economic crisis, acquisitions and firm performance. Longe Range Planning, 49(2), 171-185.

Cool, K., Dierickx, I., \& Jemison, D. (1989). Business strategy, market structure and risk-return 
relationships: A structural approach. Strategic Management Journal, 10, 507-522.

Cool, K., \& Schendel, D. (1988). Performance differences among strategic group members. Strategic Management Journal, 9(3) 207-223.

Fiegenbaum, A., \& Thomas, H. (1986). Dynamic and risk measurement perspectives on Bowman's risk-return paradox for strategic management: An empirical study. Strategic Management Journal, 7(5) 395-407.

Fiegenbaum, A., \& Thomas, H. (1988). Attitudes toward risk and the risk-return paradox: Prospect theory explanations. Academy of Management Journal, 31(1), 85-106.

Fiegenbaum, A., \& Thomas, H. (1990). Prospect theory and the risk-return association: An empirical examination of 85 industries. Journal of Economic Behaviour and Organization, 14(2), 187-203.

Fishburn, P. C. (1977). Mean-risk analysis with risk associated with below target returns. American Economic Review, 67(2), 116-126.

Gluck, F. W., Kaufman, S. P., \& Walleck, A. S. (1980, July/August). Strategic management for competitive advantage. Harvard Business Review, 154-161.

Gooding, R. Z., Goel S., \& Wiseman R. M. (1996). Fixed versus variable reference points in the risk-return relationship. Journal of Economic Behavior and Organization, 29(2), 31-350.

Harrington, S. E., Niehaus, G., \& Risko, K. J. (2002). Enterprise risk management: The case of united grain growers. Journal of Applied Corporate Finance, 14(4), 71-81.

Henkel, J. (2000). The risk-return fallacy. Schmalenbach Business Review, 52(4), 363-373.

Henkel, J. (2009). The risk-return paradox for strategic management: Disentangling true and spurious effects. Strategic Management Journal, 30(3), 287-303.

Heracleous, L., \& Werres, K. (2016). On the road to disaster: Strategic misalignments and corporate failure. Longe Range Planning, 49(4), 491-506.

Hofer, C. W., \& Schendel, D. E. (1978). Strategy formulation: Analytical concepts. (The West series in business policy \& planning). West St Paul: MN.

Hoskisson, R. E. (1987). Multidivisional structure and performance: The contingency of diversificación strategy. Academy of Management Journal, 30(4), 625-644.

Jemison, D. (1987). Risk and the relationship among strategy, organizational processes and performance. Management Science, 33(9), 1087 1101.

Johnson, H. J. (1992). The relationship between variability, distance form target, and firm size: A test of prospect theory in the comercial banking industry. Journal of Socio-Economics, 21(2), 153171.

Kahneman, D., \& Tversky, A. (1979). Prospect theory: An analysis of decisión under risk. Econometrica, 47(2), 262-291.

Kim W. C., Hwang, P., \& Burgers W. P. (1993). Multinationals' diversification and the risk-return trade-off. Strategic Management Journal, 14(4), 275-286.

Lukason, O., Laitinen, E. K., \& Suvas, A. (2016). Failure processes of young manufacturing micro firms in Europe. Management Decision, 54(8), 1966-1985.

Miller K. D., \& Bromiley, P. (1990). Strategic risk and corporate performance: An analysis of alternative risk measures. Academy of Management Journal, 33(4), 756-779. 
Miller, K. D., \& Reuer, J. J. (1996). Measuring organizational downside risk. Strategic Management Journal, 17, 671-691.

Oviatt, B. M., \& Bauerschmidt A. D. (1991). Business risk and return: a test of simultaneous relationships. Management Science, 37(11), 14051423.

Palmer, T. B., \& Wiseman R. M. (1999). Decoupling risk taking from income stream uncertainty: a holistic model of risk. Strategic Management Journal, 20, 1037-1062.

Ruefli, T. W (1990). Mean-variance approaches to risk-return relationships in strategy: paradox lost. Management Science, 36(3), 368-380.
Starkey, K. (2015). The strange absence of management during the current financial crisis. Academy of Management Review, 40(4), 652-663.

Woo, C. Y. (1987). Path analysis of the relationship between market share, business-level conduct and risk. Strategic Management Journal, 8(2), 149-168.

Zona, F. (2012). Corporate investing as a response to economic downturn: Prospect theory, the behavioural agency model and the role of financial slack. British Journal of Management, 23(1), 4257. 
Authors:

1. Rosa María Muñoz, PhD, University of Castilla-La Mancha, Ciudad Real, Spain.

E-mail: rosamaria.munoz@uclm.es

ORCID

(iD) 0000-0002-9679-5738

2. Jesús David Sánchez de Pablo, PhD, University of Castilla-La Mancha, Ciudad Real, Spain.

E-mail: jesusdavid.sanchez@uclm.es

ORCID

(iD) 0000-0002-0914-0902

3. Yolanda Salinero, PhD, University of Castilla-La Mancha, Toledo, Spain.

E-mail: yolanda.salinero@uclm.es

ORCID

(iD) 0000-0002-1404-8406

4. Isidro Peña, PhD, University of Castilla-La Mancha, Ciudad Real, Spain.

E-mail: isidro.pena@uclm.es

ORCID

(iD) 0000-0002-3742-1752

\section{Contribution of each author}

\begin{tabular}{|c|c|c|c|c|}
\hline Contribution & $\begin{array}{c}\text { Rosa } \\
\text { Muńoz }\end{array}$ & $\begin{array}{c}\text { Jesús } \\
\text { Sánchez }\end{array}$ & $\begin{array}{l}\text { Yolanda } \\
\text { Salinero }\end{array}$ & $\begin{array}{c}\text { Isidro } \\
\text { Peńa }\end{array}$ \\
\hline 1. Definition of research problem & $\sqrt{ }$ & $\sqrt{ }$ & $\sqrt{ }$ & $\sqrt{ }$ \\
\hline 2. Development of hypotheses or research questions ( empirical studies) & $\sqrt{ }$ & $\sqrt{ }$ & $\sqrt{ }$ & $\sqrt{ }$ \\
\hline 3. Development of theoretical propositions ( theoretical Work ) & $\sqrt{ }$ & $\sqrt{ }$ & & \\
\hline 4. Theoretical foundation/ Literature review & & & $\sqrt{ }$ & $\sqrt{ }$ \\
\hline 5. Definition of methodological procedures & $\sqrt{ }$ & $\sqrt{ }$ & & \\
\hline 6. Data collection & & & $\sqrt{ }$ & $\sqrt{ }$ \\
\hline 7. Statistical analysis & $\sqrt{ }$ & $\sqrt{ }$ & & \\
\hline 8. Analysis and interpretation of data & $\sqrt{ }$ & $\sqrt{ }$ & $\sqrt{ }$ & $\sqrt{ }$ \\
\hline 9. Critical revision of the manuscript & $\sqrt{ }$ & $\sqrt{ }$ & $\sqrt{ }$ & $\sqrt{ }$ \\
\hline 10. Manuscript Writing & $\sqrt{ }$ & & & \\
\hline 11. Other (please specify which) & & & & \\
\hline
\end{tabular}

